\title{
Sleeve segmentectomy for non-small cell lung carcinoma
}

\author{
Morihito Okada, MD, PhD \\ Wataru Nishio, MD, PhD \\ Toshihiko Sakamoto, MD, PhD \\ Kazuya Uchino, MD \\ Tsuyoshi Yuki, MD \\ Akio Nakagawa, MD \\ Noriaki Tsubota, MD, PhD
}

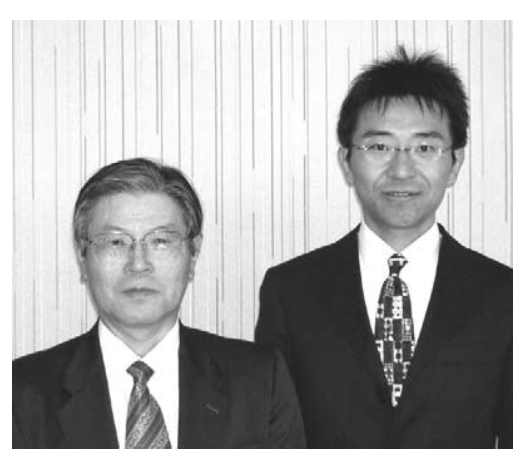

Tsubota and Okada (left to right)
From the Department of Thoracic Surgery, Hyogo Medical Center for Adults, Akashi City, Hyogo, Japan.

Received for publication Feb 19, 2004; revisions requested March 26, 2004; accepted for publication April 6, 2004.

Address for reprints: Morihito Okada, MD, $\mathrm{PhD}$, Department of Thoracic Surgery, Hyogo Medical Center for Adults, Kitaohjicho13-70, Akashi City 673-8558, Hyogo, Japan (E-mail: morihito1217jp@aol.com).

J Thorac Cardiovasc Surg 2004;128:420-4 $0022-5223 / \$ 30.00$

Copyright $\odot 2004$ by The American Association for Thoracic Surgery

doi:10.1016/j.jtcvs.2004.04.029
Objective: Although sleeve segmentectomy for centrally located lung cancers was originally designed for patients unable to tolerate lobectomy, we have tried it in patients with noncompromised function as well. We evaluated the efficiency of this atypical type of bronchoplasty.

Methods: Of 202 patients for whom we performed bronchoplasty for primary non-small cell lung carcinoma, 16 underwent sleeve segmentectomy.

Results: Sixteen patients were classified into 4 groups according to the mode of bronchial reconstruction: type A, anastomosis between the right intermediate or left main and basal segmental bronchi with removal of the superior segment of the lower lobe ( $66 ; n=7)$; type $B$, anastomosis between the left main and lingular bronchi with removal of the upper division of the left upper lobe $(\mathrm{S} 1+2+3 ; \mathrm{n}=3)$; type $\mathrm{C}$, anastomosis between the left main and upper division bronchi with removal of the lingular segments $(S 4+5 ; n=4)$; and type $D$, others $(n=2)$. Nine patients had pulmonary function sufficient to tolerate lobectomy. The tumors were completely resected in all patients. Combined performance of pulmonary angioplasty was carried out in 2 patients. Bronchial reconstruction was successful in all patients, with neither bronchial complications nor local recurrences. Ten patients had stage IA disease, and 6 had more advanced disease. All patients were alive, except 1 who died as a result of distant metastasis and 2 who died of noncancerous causes. Overall 3 -year and 5-year survivals were $93.3 \%$ and $68.1 \%$, respectively.

Conclusions: Sleeve segmentectomy, which is technically demanding, should be considered in patients with centrally located and possibly curable early non-small cell lung cancer because the prevalence of small-sized or multiple lung tumors has been increasing and because our findings suggest that this lung-saving operation is safe and useful.

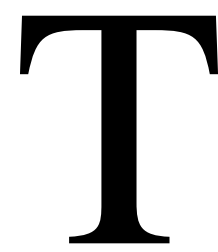

he occurrence of lung cancer has recently been increasing, and routine clinical use of spiral or high-resolution computed tomography has made detection of many small pulmonary nodules possible. We have continued to doubt whether lobectomy, which has been generally accepted as a standard form of cure for primary non-small cell lung cancer, is required for treatment of such small-sized lesions. Because lesser removal of lung parenchyma could be beneficial to patients, ${ }^{1-6}$ we have always considered pulmonary-saving procedures, even for treatment of malignant lesions. ${ }^{7-10}$ We have in fact performed pneumonectomy in only $1.3 \%$ of 749 patients treated surgically in our institution for primary lung cancer from 1999 through 2003. In addition, bronchoplastic procedures, which were reported to be usually adequate for around 5\% of patients with resectable pulmonary malignancy, ${ }^{11,12}$ has been carried out in more than $10 \%$ of our patients. ${ }^{7,8}$ 
TABLE 1. Type of procedure and reconstruction

\begin{tabular}{llll}
\hline Class & \multicolumn{1}{c}{ Lung resection } & \multicolumn{1}{c}{ Anastomosis } & Preservation \\
\hline Type A & S6 & $\begin{array}{l}\text { Right intermedial bronchi-basal segmental bronchi } \\
\text { Left main bronchi-basal segmental bronchi }\end{array}$ & Basal segments \\
Type B & Left S1+2+3 & Left main bronchi-lingular bronchi & Left S4+5 \\
Type C & Left S4+5 & Left main bronchi-upper division bronchi & Left S1+2+3 \\
Type D & Unclassified (others) & &
\end{tabular}

$S 6$, Superior segment of lower lobe; $S 1+2+3$, upper division segments; $S 4+5$, lingular segments.

The Lung Cancer Study Group's statement that limited resection triggers an increase in locoregional recurrence and death rate compared with lobectomy ${ }^{13}$ confirmed the latter to be a standard procedure of choice for tumors of any size. However, to undoubtedly accept their conclusions, of which invited commentators had a poor opinion, is risky and unfair, mainly because their trial included many cases of wedge resection and not segmentectomy as a type of lesser resection. Several studies, including prospectively performed studies, have recently demonstrated the role of segmentectomy for small-sized N0 cancer, ${ }^{5,14-18}$ and current influential data thus suggest that segmentectomy for smaller N0 cancers might be an acceptable mode of surgical treatment, even for noncompromised patients. Sleeve segmentectomy was originally designed for patients with compromised lung function who were unable to tolerate lobectomy. If segmentectomy yielded survival results at least equal to those of lobectomy in addition to better functional results, it could become an accepted procedure for patients who have anatomically suitable tumors, regardless of lung function. Functional lung parenchyma can be preserved, and the reimplanted segments will contribute to postoperative quality of life. If a second primary lung cancer develops, subsequent resection might be offered to selected patients. We have aggressively performed various atypical types of bronchial reconstructions at the segmental level in patients with noncompromised as well as compromised lung function. Because there have been very few reports summarizing the results of sleeve segmentectomy for lung cancer, we present here its significance and results obtained on continued careful follow-up.

\section{Patients and Methods}

Of 1760 patients who were operated on for primary non-small cell lung cancer from January 1988 through December 2003, 202 $(11.5 \%)$ underwent bronchoplastic procedures. Of them, 16 patients underwent sleeve segmentectomy, and we classified these patients in 4 groups (A to D) in accordance with the manner of bronchial reconstruction (Table 1).

Preoperative bronchoscopic examination was crucial in revealing the location and extent of the tumor because most of the cases could not be viewed or palpated from outside of the bronchus during the operation. Standard surgical technique was used for segmentectomy until the bronchus was encountered. ${ }^{14,15}$ Proximal and distal points of transection at the bronchus were established with at least $1 \mathrm{~cm}$ of macroscopically uninvolved distance. On the basis of results of intraoperative frozen section evaluation of both the margins, we possibly removed additional portions of the bronchus, as in case A-6 mentioned below in detail. Bronchial anastomosis was performed with interrupted sutures and full-thickness bites by using 4-0 monofilament absorbable material (polydioxanone suture, PDS-II; Ethicon, Tokyo, Japan), which was placed and tied in order from the deepest point to the lateral direction. In this type of bronchoplasty, there is generally a difference between the proximal diameter of the bronchus and the distal bronchus, which is quite thin and frail. However, the tissues there were flexible enough that careful placement of sutures could compensate for this discrepancy. A few adjusting stitches in the membranous part of the larger stump can help to make the anastomosis simpler to perform at the level of the main or lobar bronchi but not at the level of the segmental bronchi, where there are a couple of knacks for performing anastomosis. To prevent the anastomosis from progressing to stenosis, it is recommended that suturing be done to make the distal stump potentially enlarged as a mainstay of the stronger oral stump and that the bites of suture stitches and the intervals between each stitch, especially at the distal stump, be relatively short, with care being taken that the sutures do not compromise blood flow to the margins. Inside knotting of the deepest stitches is helpful, even at distal levels beyond the lobar bronchus. $^{7}$ When combined performance of angioplasty of the pulmonary artery was required, which was occasionally encountered in type $\mathrm{C}$ reconstructions, both bronchial and arterial anastomotic sites must be detached. Vascular reconstruction with a continuous 5-0 nonabsorbable polypropylene material (Prolene, Ethicon) was performed after the bronchial reconstruction. Electrocauterization or stapling (Endocutter; Ethicon Endo-Surgery, Cincinnati, Ohio) was used to divide the intersegmental plane.

Dissection or sampling of the hilar and mediastinal nodes was performed in noncompromised or compromised patients, respectively. ${ }^{19}$ Resected specimens were examined histopathologically, and histologic typing was performed according to World Health Organization classification. Surgical-pathologic staging was performed by using the New International Staging System for Lung Cancer. ${ }^{20}$ For staging and evaluation of recurrence, we carried out a physical examination, biochemical profile, chest radiographic examination, bronchoscopy, bone scintigraphy, and computed tomography of the chest, brain, and upper portion of the abdomen. Routine bronchoscopies were performed 1 and 6 months after the operation to monitor the status of the anastomosis and to rule out 
TABLE 2. Case data

\begin{tabular}{|c|c|c|c|c|c|c|c|c|c|c|c|}
\hline \multirow[b]{2}{*}{ Type } & \multirow[b]{2}{*}{ No. } & \multirow[b]{2}{*}{ Sex } & \multirow[b]{2}{*}{ Age (y) } & \multirow{2}{*}{$\begin{array}{c}\text { Histologic } \\
\text { type }\end{array}$} & \multirow[b]{2}{*}{ Resected segment } & \multicolumn{4}{|c|}{ Pathologic } & \multirow{2}{*}{$\begin{array}{l}\text { Local } \\
\text { recurrence }\end{array}$} & \multirow[b]{2}{*}{ Prognosis } \\
\hline & & & & & & $\mathbf{T}$ & $\mathbf{N}$ & M & Staging & & \\
\hline \multirow[t]{7}{*}{$A$} & $1 \dagger$ & M & 74 & SO & Left S6 & 1 & 0 & 0 & IA & No & 152 mo, alive \\
\hline & $2 \dagger$ & $M$ & 58 & SO & Right S6 & 1 & 0 & 0 & IA & No & 58 mo, deadł \\
\hline & 3 & $\mathrm{M}$ & 62 & $A D$ & Left S6 & 1 & 0 & 0 & IA & No & $57 \mathrm{mo}$, alive \\
\hline & 4 & $M$ & 74 & SQ & Right S6 & 2 & 0 & 0 & IB & No & $53 \mathrm{mo}$, dead $\ddagger$ \\
\hline & 5 & $M$ & 70 & SO & Left S6 & 1 & 1 & 0 & IIA & No & 39 mo, alive \\
\hline & $6 t$ & M & 65 & SO & Left S6 & 1 & 0 & 0 & IA & No & $38 \mathrm{mo}$, alive \\
\hline & 7 & $M$ & 59 & SO & Right S6 & 2 & 1 & 0 & IIB & No & $35 \mathrm{mo}$, alive \\
\hline \multirow[t]{3}{*}{$B$} & 1 & M & 57 & SO & Left S1+2+3 & 1 & 1 & 0 & $\| \mathrm{A}$ & No & 75 mo, alive \\
\hline & $2 \dagger$ & M & 54 & SO & Left $S 1+2+3$ & 1 & 0 & 0 & $\mathrm{IA}$ & No & $65 \mathrm{mo}$, alive \\
\hline & $3 \dagger$ & M & 61 & SO & Left S1+2+3 & 1 & 0 & 0 & IA & No & 35 mo, alive \\
\hline \multirow[t]{4}{*}{ C } & $1 \dagger$ & M & 63 & SO & Left S4+5 & 1 & 0 & 0 & IA & No & 103 mo, alive \\
\hline & $2 \dagger$ & M & 74 & SO & Left S4+5 & 1 & 0 & 0 & $\mathrm{IA}$ & No & 41 mo, alive \\
\hline & $3^{*}$ & $\mathrm{~F}$ & 76 & SO & Left S4+5 & 2 & 1 & 0 & IIB & No & $24 \mathrm{mo}$, dead§ \\
\hline & $4^{*}$ & $F$ & 69 & $A D$ & Left S4+5 & 1 & 1 & 0 & $\| A$ & No & 7 mo, alive \\
\hline \multirow[t]{2}{*}{$D$} & $1 \dagger$ & $M$ & 75 & SO & Left S1+2 & 1 & 0 & 0 & $\mathrm{IA}$ & No & 70 mo, alive \\
\hline & $2 \dagger$ & $\mathrm{F}$ & 20 & $\mathrm{ME}$ & Right S3 & 1 & 0 & 0 & IA & No & 39 mo, alive \\
\hline
\end{tabular}

$S Q$, Squamous cell carcinoma; $S 6$, superior segment of lower lobe; $A D$, adenocarcinoma; $S 1+2+3$, upper division segments; $S 4+5$, lingular segments; $S 1+2$, apical and posterior segments of upper lobe; $M E$, mucoepidermoid carcinoma; $S 3$, anterior segment of upper lobe.

*Double sleeve case (with pulmonary artery reconstruction).

tPatients with an adequate pulmonary function to tolerate lobectomy.

‡Noncancer cause.

$\S$ Distant metastasis.

local recurrence. In general, the patients were examined postoperatively at 3-month intervals for 5 years and thereafter at 1-year intervals to check for recurrence and survival. ${ }^{21}$

\section{Results}

The clinical characteristics, surgical treatment, pathologic stage, and prognosis of 16 patients in whom sleeve segmentectomy was performed are summarized in Table 2. In addition, illustrations of representative surgical procedures are provided in Figure 1. On the basis of clinical and objective functional assessment, 9 patients were considered to have pulmonary function sufficient to tolerate lobectomy, whereas the remaining 7 patients had poor functional reserve. There were 13 men and 3 women enrolled in the study, with a mean age of 64 years (range, 20-76 years). Overall follow-up ranged from 7 to 152 months, with a median of 46 months. Histologic cell type was squamous cell carcinoma in $13(81 \%)$ patients, adenocarcinoma in 2 (13\%) patients, and mucoepidermoid carcinoma in $1(6 \%)$ patient. Complete resection was performed in all patients. Angioplasty of the pulmonary artery, so-called doublesleeve resection, was performed in 2 patients classified as type C. On surgical-pathologic staging, 10 (63\%) patients had stage IA disease, 1 had stage IB disease, 3 had stage IIA disease, and 2 had stage IIB disease. There was no operative mortality, which was defined as death within 30 days after the operation. Postoperative complications were infrequent and nonfatal, with bacterial pneumonia and bronchial asthma occurring in 1 patient each. In all patients bronchial reconstruction was successful, and neither stenosis nor local recurrence at the anastomotic site, reimplanted lung, or regional lymph node involvement had developed by the time of this report. However, 1 patient with stage IIB disease died 2 years after the operation as a result of distant metastasis, and 2 patients died of noncancerous causes. Overall 3-year and 5-year survivals were $93.3 \%$ and $68.1 \%$, respectively.

\section{Discussion}

Generally, making the decision whether to perform bronchoplasty for malignancy depends on a subtle balance among postoperative quality of life, risk of recurrence, and postoperative complications. One of the greatest concerns about sleeve segmentectomy is the potentially increased rate of local recurrence, although no local recurrence has occurred in this series. In any case, it is essential to ensure a macroscopically sufficient margin of safety, as well as to examine it with rapid frozen sections intraoperatively. The rate of postoperative complications, which were nonfatal and minor respiratory problems, was generally low in the present series, and survival after the operation was not poor. Hilar lung cancer has a tendency to occur multicentrically, and therefore the goal of radical surgical intervention should be to maintain as much lung function as possible because the initial mode of the operation influences the resectability 
of secondary disease. We have carried sleeve segmentectomy actively not only in compromised patients but also in noncompromised patients. In the latter group, if an intraoperative pathologic examination points out that the disease can be advanced, the procedure will be modified to the standard one, such as lobectomy or sleeve lobectomy, with complete systematic dissection of the lymph nodes. Most surgeons might have chosen lobectomy for the noncompromised patients and not performed thoracotomy for the compromised patients in this series. Sleeve segmentectomy, for which hilar cancer with negative nodes is the most suitable indication, should be considered, even for noncompromised patients. Two representative cases will be presented. One patient (case A-6; Figure 1, A) intentionally underwent left sleeve S6 (superior segment of lower lobe) segmentectomy with partial resection of the upper lobe bronchus because his disease had invaded beyond the second carina. In addition, the distal bronchial stump was trimmed with convex wedgeshaped cutting to complete the anastomosis because the lesion also involved the bronchial wall toward the basal segment. The other patient (case C-4; Figure 1, B) underwent sleeve lingulectomy ( $\mathrm{S} 4+5)$ with sleeve angioplasty of the pulmonary artery, so-called double-sleeve resection. To our knowledge, there have been no previous reports concerning double-sleeve resection at the level of the segment. The artery was freed proximally and distally to allow anastomosis without tension and reconstructed with a pericardial patch. Because the patient's preoperative values of forced expiratory volume in 1 second and forced expiratory volume in 1 second/forced vital capacity were $0.85 \mathrm{~L}$ and $37 \%$, respectively, high-frequency jet ventilation was applied to inflate the left upper division segments detached during the procedure of anastomosis, accompanied by intermittent positive-pressure ventilation to the right lung.

These patients have recovered uneventfully. Endobronchial interventions, such as YAG laser cauterization, brachytherapy, and photodynamic therapy, can be therapeutic options for very early hilar cancer located at sites that can be directly viewed with a bronchoscope. These techniques, however, cannot accurately address the depth of invasion, free margins, or nodal status, and complete remission can be obtained only in carcinoma in situ or microinvasive cancer. We believe that except for selected patients in whom radical treatment can definitely be performed with these endoluminal interventions, thoracotomy is more reliable at present. When segmentectomy, with or without bronchoplasty, is planned in noncompromised patients, dissected lymph nodes should undergo intraoperative frozensection pathologic examination to confirm the absence of metastasis because this information is needed for a diagnosis of early cancer. The results of this study clearly demonstrate that sleeve segmentectomy is a satisfactory surgical
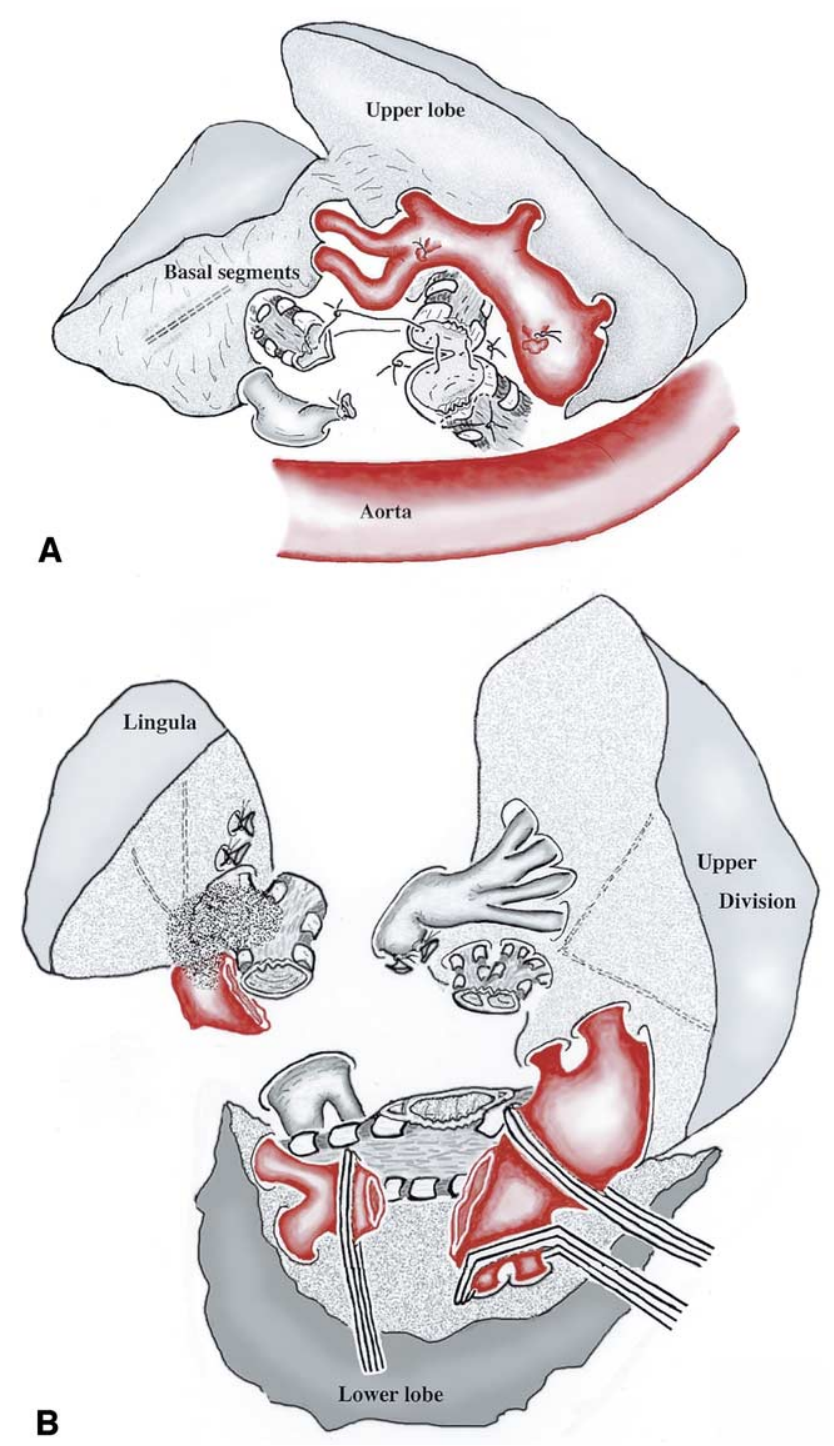

Figure 1. Schematic illustrations of representative surgical findings. A, Case A-6: left sleeve S6 (superior segment of lower lobe) segmentectomy with additional deep wedge resection of the second carina caused by involvement of the lesion. The distal bronchial stump was trimmed with convex wedge-shaped cutting because the lesion also extended to the basal segmental bronchus. B, Case C-4: left sleeve lingulectomy $(\mathbf{S} 4+5)$ with a sideto-end anastomosis between the left main and the cut end of the upper division of the bronchi, and sleeve resection of the pulmonary artery with subsequent reconstruction using a pericardial patch (so-called double-sleeve resection).

option for hilar lung cancer, as regards both operative risk and curability. The indications for this procedure, which is technically more demanding than lobectomy, need to be thoroughly clarified. We suggest that sleeve segmentectomy should be considered an option for small-sized, centrally located, N0 non-small cell lung cancer when feasible. 


\section{References}

1. Read RC, Yoder G, Schaeffer RC. Survival after conservative resection for T1 N0 M0 nonsmall cell lung cancer. Ann Thorac Surg. 1990;49:391-8.

2. Jensik RJ, Faber LP, Milloy FJ, Monson DO. Segmental resection for lung cancer. A fifteen-year experience. J Thorac Cardiovasc Surg. 1973;66:563-72.

3. Miller JI Jr, Hatcher CR Jr. Limited resection of bronchogenic carcinoma in the patient with marked impairment of pulmonary function. Ann Thorac Surg. 1987;44:340-3.

4. Warren WH, Faber LP. Segmentectomy versus lobectomy in patients with stage I pulmonary carcinoma. Five-year survival and patterns of intrathoracic recurrence. J Thorac Cardiovasc Surg. 1994;107:108793.

5. Kodama K, Doi O, Higashiyama M, Yokouchi H. Intentional limited resection for selected patients with T1 N0 M0 non-small-cell lung cancer: a single-institution study. J Thorac Cardiovasc Surg. 1997; 114:347-53.

6. Pastorino U, Valente M, Bedini V, Infante M, Tavecchio L, Ravasi G. Limited resection for Stage I lung cancer. Eur J Surg Oncol. 1991;17: 42-6.

7. Okada M, Tsubota N, Yoshimura M, Miyamoto Y, Matsuoka H, Satake S, et al. Extended sleeve lobectomy for lung cancer: the avoidance of pneumonectomy. J Thorac Cardiovasc Surg. 1999;118: 710-3.

8. Okada M, Yamagishi H, Satake S, Matsuoka H, Miyamoto Y, Yoshimura M, et al. Survival related to lymph node involvement in lung cancer after sleeve lobectomy compared with pneumonectomy. J Thorac Cardiovasc Surg. 2000;119:814-9.

9. Okada M, Sakamoto T, Nishio W, Uchino K, Tsubota N. Characteristics and prognosis of patients after resection of nonsmall cell lung carcinoma measuring $2 \mathrm{~cm}$ or less in greatest dimension. Cancer. 2003;98:535-41.

10. Okada M, Nishio W, Sakamoto T, Uchino K, Tsubota N. Discrepancy of computed tomographic image between lung and mediastinal win- dows as a prognostic implication in small lung adenocarcinoma. Ann Thorac Surg. 2003;76:1828-32.

11. Lowe JE, Bridgman AH, Sabiston DC Jr. The role of bronchoplastic procedures in the surgical management of benign and malignant pulmonary lesions. J Thorac Cardiovasc Surg. 1982;83:227-34.

12. Tedder M, Anstadt MP, Tedder SD, Lowe JE. Current morbidity, mortality, and survival after bronchoplastic procedures for malignancy. Ann Thorac Surg. 1992;54:387-91.

13. Ginsberg RJ, Rubinstein LV. Randomized trial of lobectomy versus limited resection for T1 N0 non-small cell lung cancer. Lung Cancer Study Group. Ann Thorac Surg. 1995;60:615-22.

14. Okada M, Yoshikawa K, Hatta T, Tsubota N. Is segmentectomy with lymph node assessment an alternative to lobectomy for non-small cell lung cancer of $2 \mathrm{~cm}$ or smaller? Ann Thorac Surg. 2001;71:956-60.

15. Tsubota N, Ayabe K, Doi O, Mori T, Namikawa S, Taki T, et al. Ongoing prospective study of segmentectomy for small lung tumors. Study Group of Extended Segmentectomy for Small Lung Tumor. Ann Thorac Surg. 1998;66:1787-90.

16. Yoshikawa K, Tsubota N, Kodama K, Ayabe H, Taki T, Mori T. Prospective study of extended segmentectomy for small lung tumors: the final report. Ann Thorac Surg. 2002;73:1055-8.

17. Miller DL, Rowland CM, Deschamps C, Allen MS, Trastek VF, Pairolero PC. Surgical treatment of non-small cell lung cancer $1 \mathrm{~cm}$ or less in diameter. Ann Thorac Surg. 2002;73:1545-50.

18. Sagawa M, Koike T, Sato M, Oda M, Kondo T, Kato H, et al. Segmentectomy for roentgenographically occult bronchogenic squamous cell carcinoma. Ann Thorac Surg. 2001;71:1100-14.

19. Okada M, Tsubota N, Yoshimura M, Miyamoto Y. Proposal for reasonable Mediastinal lymphadenectomy in bronchogenic carcinomas: role of subcarinal nodes in selective dissection. J Thorac Cardiovasc Surg. 1998;116:949-53.

20. Mountain CF. Revisions in the International System for Staging Lung Cancer. Chest. 1997;111:1710-7.

21. Okada M, Nishio W, Sakamoto T, Harada H, Uchino K, Tsubota N. Long-term survival and prognostic factors of five-year survivors with complete resection of non-small cell lung carcinoma. J Thorac Cardiovasc Surg. 2003;126:558-62.

\section{Availability of Journal back issues}

As a service to our subscribers, copies of back issues of The Journal of Thoracic and Cardiovascular Surgery for the preceding 5 years are maintained and are available for purchase from Elsevier Inc. until inventory is depleted. Please write to Elsevier Inc., Subscription Customer Service, 6277 Sea Harbor Dr, Orlando, FL 32877 or call $800-654-2452$ or $407-345-4000$ for information on availability of particular issues and prices. 